\title{
Tyrphostin AG 556 Improves Survival and Reduces Multiorgan Failure in Canine Escherichia Coli Peritonitis
}

\author{
Jonathan E. Sevransky, ${ }^{\star}$ Gade Shaked, ${ }^{\star}$ Abraham Novogrodsky, ${ }^{\|}$Alexander Levitzki,, Aviv Gazit, ${ }^{\rrbracket}$ Amnon Hoffman,, \\ Ronald J. Elin, ${ }^{\ddagger}$ Zenaide M.N. Quezado, ${ }^{\star}$ Bradley D. Freeman, ${ }^{\star}$ Peter Q. Eichacker, ${ }^{\star}$ Robert L. Danner, ${ }^{\star}$ \\ Steven M. Banks, ${ }^{\star}$ John Bacher ${ }^{\S}$ Marvin L. Thomas III, ${ }^{\S}$ and Charles Natanson* \\ $*$ Department of Critical Care Medicine, ${ }^{\ddagger}$ Department of Clinical Pathology, and the ${ }^{\S}$ Veterinary Resources Program, National Institutes of \\ Health, Bethesda, Maryland 20892; "Felsenstein Medical Research Center, Petach Tikva, and Sackler Faculty of Medicine, Tel Aviv \\ University, Israel 69978; and the "Department of Biological Chemistry and the **Department of Pharmaceutics, Hebrew University of \\ Jerusalem, Israel 91904
}

\begin{abstract}
Tyrosine kinase-dependent cell signaling is postulated to be a pivotal control point in inflammatory responses initiated by bacterial products and TNF. Using a canine model of gram-negative septic shock, we investigated the effect of tyrosine kinase inhibitors (tyrphostins) on survival. Animals were infected intraperitoneally with Escherichia coli 0111: $\mathrm{B} 4$, and then, in a randomized, blinded fashion, were treated immediately with one of two tyrphostins, AG 556 $(n=40)$ or AG $126(n=10)$, or with control $(n=50)$, and followed for $28 \mathrm{~d}$ or until death. All animals received supplemental oxygen, fluids, and antibiotics. Tyrphostin AG 556 improved survival times when compared to controls $(P=0.05)$. During the first $48 \mathrm{~h}$ after infection, AG 556 also improved mean arterial pressure, left ventricular ejection fraction, cardiac output, oxygen delivery, and alveolar-arterial oxygen gradient compared to controls (all $P \leq 0.05$ ). These improvements in organ injury were significantly predictive of survival. Treatment with AG 556 had no effect on clearance of endotoxin or bacteria from the blood (both $P=$ NS); however, AG 556 did significantly lower serum TNF levels $(P=\mathbf{0 . 0 3})$. These data are consistent with the conclusion that AG 556 prevented cytokine-induced multiorgan failure and death during septic shock by inhibiting cell-signaling pathways without impairing host defenses as determined by clearance of bacteria and endotoxin. (J. Clin. Invest. 1997. 1966-1973.) Key words: tyrosine kinase inhibitor • cell signaling pathways $\bullet$ septic shock $\bullet$ multiorgan failure
\end{abstract}

\section{Introduction}

Sepsis and septic shock are major causes of morbidity and mortality in hospitalized patients $(1,2)$. Despite infection control measures, effective antibiotics, and supportive therapies such as intravenous fluid and vasopressors, the incidence of this syndrome has increased over the last decade, and the mortality rate $(35-50 \%)$ has not changed (1-7). Thus, researchers

Address correspondence to Jonathan E. Sevransky, M.D., Critical Care Medicine Department, National Institutes of Health, Building 10, Room 7D-43, 9000 Rockville Pike, Bethesda, MD 20892-1662. Phone: 301-496-9320; FAX: 301-402-1213; E-mail: jsevransky@nih.gov

Received for publication 10 December 1996 and accepted in revised form 6 February 1997.

The Journal of Clinical Investigation

Volume 99, Number 8, April 1997, 1966-1973 continue to investigate new therapies to treat this lethal syndrome.

Septic shock is thought to result from the release of proinflammatory cytokines (e.g., tumor necrosis factor-alpha [TNF- $\alpha$ ],

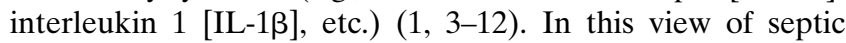
shock pathogenesis, endotoxin and other bacterial products initiate an inflammatory response by activating sentinel cells that release cytokines, including TNF- $\alpha$ and IL-1 $\beta$ (1, 8-13). These cytokines amplify the inflammatory response by inducing target cells to release additional and potentially harmful host mediators such as cytokines, eicosanoids, and nitric oxide (1, 8-13). Supporting this model, endotoxin and recombinant TNF- $\alpha$ or IL- $1 \beta$ reproduce many of the manifestations of septic shock in both humans and animals (11-15). Furthermore, therapies directed against endotoxin (10), TNF- $\alpha$ (8), and IL-1 $\beta$ (9) improve survival in animal models. These preclinical results, however, have not translated into significant beneficial outcomes in human clinical trials of anticytokine and antiendotoxin therapies in sepsis $(1,3-7)$. It is unknown if this failure relates to the bioactivity of the agents studied, the methodologies used, or the hypotheses tested $(1,16,17)$.

Tyrosine kinase inhibitors represent a new approach for treating sepsis. Most previous attempts at blocking inflammation during sepsis have been limited to targeting a single mediator in one compartment of the body (i.e., the circulation) (1, 3-10). In contrast, tyrosine kinase inhibitors act directly on cells, not mediators. Specifically, macrophage responses to LPS, including TNF- $\alpha$ and IL- $1 \beta$ synthesis, eiconsanoid production, and enhancement of macrophage tumor killing, all occur via activation of tyrosine kinases (18-23). In addition, target cell activation by TNF- $\alpha$ and IL- $1 \beta$ also occurs through tyrosine phosphorylation signaling pathways. Therefore, many of the known cellular effects of LPS and cytokines can be blocked by tyrosine kinase inhibitors (18-23). In effect, tyrosine kinase inhibitors target multiple mediators of sepsis simultaneously, and depending on the pharmacokinetic properties of the particular tyrphostin used, have the potential to reach therapeutic concentrations in a variety of body compartments.

Recently, a family of tyrosine kinase inhibitors, tyrphostins, which are derivatives of benzylidene malononitrile, have undergone extensive in vitro and in vivo studies. Tyrphostin AG 126, when given before endotoxin, lowered levels of TNF- $\alpha$ produced by murine peritoneal macrophages when measured by either ELISA or bioassay (18). In vitro TNF- $\alpha$ cytotoxicity was reduced by AG 126 when added to mouse A9 fibroblasts. AG 126 also inhibited the phosphorylation of a $42-\mathrm{kD}$ mitogenactivated protein kinase. Importantly, AG 126, when administered before LPS challenge, produced a survival benefit in mu- 
rine models (18). In vitro, a more lipophilic tyrphostin, AG 556, prevented LPS-induced activation of protein kinase hck, (an early step in cell activation after LPS challenge) in mouse peritoneal macrophages. AG 556 also reduced mortality in murine models when given up to $2 \mathrm{~h}$ after either LPS administration, or a peritoneal E. coli O55:B5 infection (22).

We have developed a canine model to simulate some of the cardiovascular abnormalities of human septic shock (24-27), and have shown that the standard therapies used in patients are beneficial in this model (26). We studied the effects of the tyrphostins AG 556 and AG 126 on survival and multiorgan failure in this canine model.

\section{Methods}

Study drugs. The tyrphostins used were synthesized as previously described $(28,29)$. They were dissolved in $0.5 \mathrm{mg} \cdot \mathrm{kg}^{-1}$ dimethyl sulfoxide (DMSO) (99.9\% purity) (Sigma Chemical Corp., St. Louis, MO), and added to $250 \mathrm{ml} 0.9 \%$ saline with $25 \mathrm{meq} \mathrm{NaHCO}_{3}$. The control animals received $0.5 \mathrm{mg} \cdot \mathrm{kg}^{-1}$ DMSO in $250 \mathrm{ml} 0.9 \%$ saline with 25 meq $\mathrm{NaHCO}_{3}$. The doses of AG $556\left(2.5 \mathrm{mg} \cdot \mathrm{kg}^{-1}\right.$ every $\left.6 \mathrm{~h} \times 2\right)$ and AG $126\left(10 \mathrm{mg} \cdot \mathrm{kg}^{-1}\right.$ every $\left.6 \mathrm{~h} \times 2\right)$ were chosen based on results from canine leukocyte experiments (see Results) and murine sepsis models $(18,22)$.

Study design. All animals were observed after placement of an intraperitoneal E. coli-infected clot for 28 d, or until death. Because we were unable to study more than four animals simultaneously, only four animals were entered into the study each week for $25 \mathrm{wk}$. Animals were observed continuously for the first $36 \mathrm{~h}$ after clot implantation. Any unobserved death was considered to have occurred when the animal was found. The duration of survival (h) was determined from the time of clot implantation. As prospectively determined, any animal killed before completion of the 28-day study was considered a nonsurvivor, and was included in the analysis. Animals were randomly assigned to a treatment arm, and investigators were blinded to the animals' treatment. Only one of the statisticians (David W. Alling) who monitored weekly survival results knew which treatment the animals received. In the first stage of this study, 40 animals were used: 10 received AG 556, 10 received AG 126, and 20 received vehicle alone (controls). After analysis of the 40 animals, we initiated a second phase of the study, comparing the efficacy of AG 556 vs. control in an additional 60 animals (see Statistical methods).

Animal model. 1-2-yr-old 10-12 kg purpose-bred beagles were studied. Only intraperitoneal placement of the fibrin-thrombin clot on day 0 required general anesthesia. Intravascular catheters were placed on days 0,2 , and 28 with subcutaneous infiltration of local anesthetic ( $1 \%$ lidocaine); they were removed each day after completion of hemodynamic and laboratory evaluations $(24-27,30)$.

On the day of surgery (day 0 ), animals were given a short-acting intramuscular sedative-analgesic $\left(2 \mathrm{mg} \cdot \mathrm{kg}^{-1}\right.$ of xylazine hydrochloride with $0.03 \mathrm{mg} \cdot \mathrm{kg}^{-1}$ of atropine sulfate). Animals then had an 8.5 french intravenous catheter percutaneously placed into the external jugular vein. Intraoperative fluids were given $\left(50 \mathrm{ml} \cdot \mathrm{kg}^{-1}\right.$ of $0.9 \%$ saline over $30 \mathrm{~min}$ ). After mask induction of anesthesia by inhalation of isoflurane, the trachea was intubated. Inhaled isoflurane concentration was maintained at $1-3 \%$ in $100 \%$ oxygen, and animals breathed spontaneously during intraperitoneal placement of an infected $(7.5 \times$ $10^{9}$ colony-forming units E. coli, $0111: \mathrm{B} 4 \cdot \mathrm{kg}^{-1}$ of body weight) fibrinthrombin clot which was prepared using previously described methods (24-27, 30). After closure of the laparotomy, $6 \mathrm{ml}$ of $0.25 \%$ bupevicaine hydrochloride was injected subcutaneously around the laparotomy incision, and then the isoflurane was discontinued and animals were extubated when awake. This surgical procedure lasted approximately $30 \mathrm{~min}$

Therapeutic interventions. Directly after clot implantation, animals received a tyrphostin or vehicle infusion in a light-shielded infusion bag intravenously over $30 \mathrm{~min}$. Ceftriaxone sodium (HoffmannLaRoche Laboratories, Nutley, NJ) $100 \mathrm{mg} \cdot \mathrm{kg}^{-1}$ was given intravenously $6 \mathrm{~h}$ after clot implantation, and then once a day for $5 \mathrm{~d}$. Immediately after the 6-h antibiotic dose, the infusion of tyrphostin or vehicle alone (control) was repeated. A fluid infusion of $10 \mathrm{ml} \cdot \mathrm{kg}^{-1}$ Ringer's solution was given from $6-30 \mathrm{~h}$. For the first $30 \mathrm{~h}$ of the experiment, a total of $410 \mathrm{ml} \cdot \mathrm{kg}^{-1}$ of Ringer's solution was given to animals in all groups. The fluid requirements were based on previous studies in animals where infected animals were continuously monitored with arterial and Swan-Ganz catheters to guide fluid therapy (26). Animals were maintained in Kirschner cages (Plas-Labs, Lansing, MI) at $27^{\circ} \mathrm{C}$ with oxygen infused to keep the fraction of inspired oxygen $\left(\mathrm{FiO}_{2}\right)=$ $40 \%$ from $6-30 \mathrm{~h}$. Animals were only removed for $30 \mathrm{~min}$ from cages at 9 and $24 \mathrm{~h}$ to allow equilibration with room air for hemodynamic evaluations, and were then immediately returned to the Kirschner cages. Animals had unrestricted access to food and water throughout the study, except for $12 \mathrm{~h}$ before the surgery.

Hemodynamics and blood chemistries. For baseline evaluation, we measured hemodynamic and laboratory values at least $7 \mathrm{~d}$ before clot implantation. Data were obtained from femoral arterial and balloon flotation thermodilution pulmonary arterial catheters inserted using local anesthesia. Moments later, a fluid challenge of Ringer's solution $\left(80 \mathrm{ml} \cdot \mathrm{kg}^{-1}\right.$ of body wt over $30 \mathrm{~min}$ ) was given, and the hemodynamic studies were repeated. To determine the serial effects of sepsis over $28 \mathrm{~d}$, we repeated the same hemodynamic and blood chemistry evaluation performed at baseline on days 1, 2, and 28 after surgery. At $9 \mathrm{~h}$ postsurgery, hemodynamic values were obtained without the fluid challenge. Measurements included heart rate (beats $\cdot \mathrm{min}^{-1}$ ), mean arterial pressure (MAP, $\mathrm{mmHg}$ ), ${ }^{1}$ central venous pressure $(\mathrm{mmHg})$, mean pulmonary artery pressure $(\mathrm{mmHg})$, pulmonary capillary wedge pressure (PCWP, $\mathrm{mmHg}$ ), and cardiac output $\left(\mathrm{ml} \cdot \mathrm{min}^{-1}\right)(24-27,30)$. To determine left ventricular ejection fraction, we performed radionuclide-gated blood pool scans using previously described techniques $(24-27,30)$. Hemodynamic data were indexed to body weight in kilograms. Cardiac index $\left(\mathrm{CI}, \mathrm{ml} \cdot \mathrm{min}^{-1}\right.$ per $\left.\mathrm{kg}^{-1}\right)$, stroke volume index $\left(\mathrm{ml} \cdot \mathrm{kg}^{-1}\right)$, left ventricular stroke work index $\left(\mathrm{g} \cdot \mathrm{ml}^{-1}\right.$ per $\left.\mathrm{kg}^{-1}\right)$, systemic vascular resistance index $(\mathrm{dyn} \cdot \mathrm{s}$ per $\mathrm{cm}^{-5}$ per $\left.\mathrm{kg}^{-1}\right)$, oxygen delivery index $\left(\mathrm{DO}_{2} \mathrm{I}, \mathrm{ml} \cdot \mathrm{min}^{-1}\right.$ per $\left.\mathrm{kg}\right)$, end diastolic volume index $\left(\mathrm{ml} \cdot \mathrm{kg}^{-1}\right)$, end systolic volume index $\left(\mathrm{ml} \cdot \mathrm{kg}^{-1}\right)$, and alveolar-arterial oxygen gradient (AaPo2, Torr) were calculated using standard formulas.

Arterial and mixed venous blood gases were measured at $37^{\circ} \mathrm{C}$ with a blood gas system (model 288; CBI-Corning, Medfield, MA). Blood lactate levels were measured using a glucose-lactate analyzer (model 2300 STAT; Yellow Springs Instrument Co., Yellow Springs, $\mathrm{OH})$. Complete blood counts were performed using an automatic analyzer (model STK-S; Coulter Electronics, Hialeah, FL). Measurements of electrolyte levels and chemical analyses of the blood (e.g., calcium [Ca], phosphorus, glucose, urea nitrogen, creatinine, uric acid [UA], alanine aminotransferase [ALT], albumin [Alb], aspartate aminotransferase [AST], gamma-glutamyl-transpeptidase [GGTP], alkaline phosphatase, lactate dehydrogenase, total bilirubin, triglyceride, and cholesterol levels) were done using an automated chemistry analyzer (model AU 500; Olympus, Irving, TX). On day 0, blood was obtained in pyrogen-free tubes for endotoxin and TNF levels, and quantitative blood cultures, at the times shown (see Fig. 5, $A$ and $B$ ). Endotoxin concentrations were determined from heparinized plasma that was diluted, heat-treated, and then assayed using a kinetic modification of the chromogenic Limulus amebocyte lysate assay (Whittaker Bioproducts, Walkersville, MD), as previously described (27).

1. Abbreviations used in this paper: $\mathrm{AaPO}_{2}$, alveolar-arterial oxygen gradient; ALT, alanine aminotransferase; AST, aspartate aminotransferase; CI, cardiac index; $\mathrm{DO}_{2} \mathrm{I}$, oxygen delivery index; GGTP, gamma glutamyl transpeptidase; IS, internal standard; MAP, mean arterial pressure. 
TNF concentrations were determined with a quantitative TNF cytotoxicity assay using WEHI 164 cells in 96-well plates; results were calculated based on the values obtained from a recombinant human TNF standard, as previously described (30).

Tyrphostin levels. On day 0, tyrphostin serum levels were determined 5 and 15 min after the first dose of tyrphostin (immediately after infected clot implantation), and 5 and 15 min after the second dose of tyrphostin ( $6 \mathrm{~h}$ after infected clot implantation). Animal serum samples were analyzed for tyrphostin levels in a blinded fashion. First, as an internal standard (IS), another tyrphostin, AG-17 (0.3 mg/ $\mathrm{ml}$ ) in methanol, was added to $100 \mu \mathrm{l}$ of the serum sample. Following vortexing, $30 \mu \mathrm{l}$ of $0.3 \% \mathrm{HCl}$ solution were transferred into the test tube, and $1 \mathrm{ml}$ of $t$-butylmethyl ether was then added. The drug and IS were next extracted. To assure complete extraction of drug and IS, the two-phase mixture was thoroughly mixed by vortexing for $120 \mathrm{~s}$, and the phases were then separated by $10 \mathrm{~min}$ of high-speed centrifugation. The organic phase (upper phase) was collected and evaporated to dryness under vacuum. The dry residue was then reconstituted in $100 \mu \mathrm{l}$ methanol, and $20 \mu \mathrm{l}$ of the methanolic solution was injected into the high pressure liquid chromatograph. The chromatography was carried out using a RP-18 column with particle size of $5 \mu \mathrm{m}$, and a mobile phase containing acetonitrile $70 \%$ in water with $0.05 \%$ trifluoroacetic acid. The concentration of the drug was determined spectrophotometrically at a wavelength of $363 \mathrm{~nm}$. Drug concentrations were determined on the appropriate standard curves.

In vitro study. Peripheral canine mononuclear cells were obtained from heparinized peripheral blood as follows. After centrifugation at $170 \mathrm{~g}$ for $10 \mathrm{~min}$ at $4^{\circ} \mathrm{C}$, the cell pellet was resuspended in RPMI 1640 containing heat-inactivated newborn calf serum (20\%). Adherent macrophage monolayers were obtained by plating of the cells in 96-well microtiter plates at $2 \times 10^{6}$ cells per well, and incubation for $2 \mathrm{~h}$ at $37^{\circ} \mathrm{C}$ in $5 \% \mathrm{CO}_{2}$. Nonadherent cells were removed, and fresh medium (RPMI 1640 containing heat-inactivated newborn calf serum) was added. After incubation of macrophage monolayers for $24 \mathrm{~h}$, tyrphostins were added (AG 126 at $50 \mu \mathrm{M}$ and AG 556 at 10, 20, and $50 \mu \mathrm{M}$ ) and incubated for $1 \mathrm{~h}$ before the addition of $10 \mu \mathrm{g} / \mathrm{ml}$ endotoxin (Sigma). After incubation for $24 \mathrm{~h}, \mathrm{TNF}-\alpha$ concentrations were determined by a biological assay using A9 mouse fibroblast cell lines (18). The studies were done in duplicate using cells from two animals.

Studies in noninfected animals. In normal animals, intravascular catheters were placed, and hemodynamic and laboratory studies were performed as done in infected animals at baseline. Animals were given AG 126, AG 556, or control solutions in a manner similar to infected animals, but without surgical placement of an infected clot. All of the baseline hemodynamic and laboratory studies were repeated at 1,4 , and $24 \mathrm{~h}$ after drug infusion. Two animals received AG 126 at $40 \mathrm{mg} /$ $\mathrm{kg}$, two animals received AG 126 at $20 \mathrm{mg} / \mathrm{kg}$, and one animal received AG 126 at $10 \mathrm{mg} / \mathrm{kg}$. Three animals were given AG 556 at $6.25 \mathrm{mg} / \mathrm{kg}$. Seven control animals received vehicle alone, $0.5 \mathrm{mg} / \mathrm{kg}$ of DMSO.

Animal care. This experimental protocol was approved by the Animal Care and Use Committee of the Clinical Center of the National Institutes of Health. Throughout the studies, all efforts were taken to minimize animal pain and suffering.

Statistical methods. We planned and carried out a two-stage adaptive design for our blinded study. 40 animals (20 control, 10 treated with AG 556, and 10 treated with AG 126) were admitted to the first stage, at the end of which survival was evaluated (see Fig. 1 A). AG 126 treatment was no better than control, whereas AG 556 treatment appeared beneficial. After an interim analysis, it was decided to terminate the AG 126 arm (descriptive level, Dunnett test $P=0.42$ ), but to continue the study of AG 556 (Dunnett test $P=$ 0.106 ) in a second stage consisting of 60 animals ( 30 controls, $30 \mathrm{AG}$ 556). At the end of the second stage, we compared overall results for animals treated with AG 556 and controls using a statistical method described by Bauer and Kohne (31). In their notation, we had set bounds on $P_{1}$, the first-stage descriptive level of significance, at $0.00575\left(\alpha_{1}\right)$ and at $0.2\left(\alpha_{2}\right)$. Thus, a value of $P_{1}$ less than $\alpha_{1}$ would have led to rejection of the null hypothesis, whereas a value greater than 0.2 would have led to an acceptance of the null hypothesis (In fact $\left.P_{1}=0.106\right)$. An upper bound of 0.5 on $P_{2}$, conditional on $P_{1}$ being greater than 0.0575 , was also set. Since the descriptive level of significance (log rank test) for the second stage was $P_{2}=0.00577$, the product of $P_{1}$ and $P_{2}$ used in the Fisher omnibus test was $P_{1} P_{2}=$ 0.006116. Calculations like those leading to equation 3 of the reference yield an overall (one-sided) type 1 error probability of 0.026 , which results in a two-sided value of 0.052 .

For hemodynamic, pulmonary, and laboratory parameters, an ANOVA (32) was performed. Only control or AG 556 animals were included in the ANOVA, and as no interim look at these data was performed, the $P$-value was not adjusted. At baseline, a one-way ANOVA was used to demonstrate that no significant differences existed between control and AG 556. A three-way ANOVA was performed, with effects for treatment, dog (nested within treatment), and time as the main effects. In addition, the two-way treatment time interaction was examined. All other interactions were pooled to form the error term for the ANOVA. Data were transformed using either a logarithmic or square root transformation if a Shapiro-Wilk test indicated significant departure in the normality of the residuals. Spearman correlations between survival times and those hemodynamic and laboratory parameters that were found to have significant differences in time course were also computed.

Tyrphostin levels at 5 and 15 min after two different infusion times were also analyzed by a three-way ANOVA. In addition, the half-life of AG 556 was estimated when a 5-min value was greater than a nonzero 15-min value for all animals receiving AG 556.

Serial TNF levels were initially analyzed by an ANOVA, but large variability at baseline (even in a transformed scale), led to nonsignificant results. A summary statistic based on previous analyses of canine model data (30) was computed as follows: the maximum TNF level observed between 1 and $9 \mathrm{~h}$ was divided by the minimum value seen outside this time period to yield a normalized percent increase summary statistic. This summary statistic was analyzed by ANOVA with treatment group and survival status as the two main effects. The reported data (see Table I) show the computed mean maximal increases, which is the product of the mean percent increase and the average baseline TNF level $(2.9 \pm 0.9 \mathrm{ng} / \mathrm{ml})$.

\section{Results}

Clinical manifestations and survival. During the $4 \mathrm{~d}$ after surgery, all animals had typical signs of sepsis (appearing weak, lethargic, and anorexic). No animal died within the first $6 \mathrm{~h}$ after infected clot implantation. The following animals were killed by a veterinarian who was unaware of the assigned treatment group: between 20 and $27 \mathrm{~h}$, three animals in the AG 556 group and two in the control group with intractable seizures; between 27 and $48 \mathrm{~h}$, two animals in the control group with respiratory failure and, at day 17, one animal in the AG 556 group with persistent nausea, vomiting, and inanition. As prospectively determined, all of these animals were included in the analysis, and were considered to be nonsurvivors with a survival time equivalent to the time of death. The survival times of AG 556-treated animals were significantly improved compared to controls $(P=0.05$; Fig. $1 C)$. The survival times of AG 126-treated animals were not significantly different compared with controls $(P=\mathrm{NS}$; Fig. $1 A)$.

Cardiopulmonary. Cardiopulmonary measurements obtained at the baseline time point were not significantly different in the AG 556 animals vs. controls $(P=\mathrm{NS}$; data not shown). In AG 556-treated animals at 9, 24, and $48 \mathrm{~h}$ after infected clot, the fall in mean MAP, left ventricular ejection fraction, $\mathrm{CI}, \mathrm{DO}_{2} \mathrm{I}$, and PCWP were significantly less compared to 


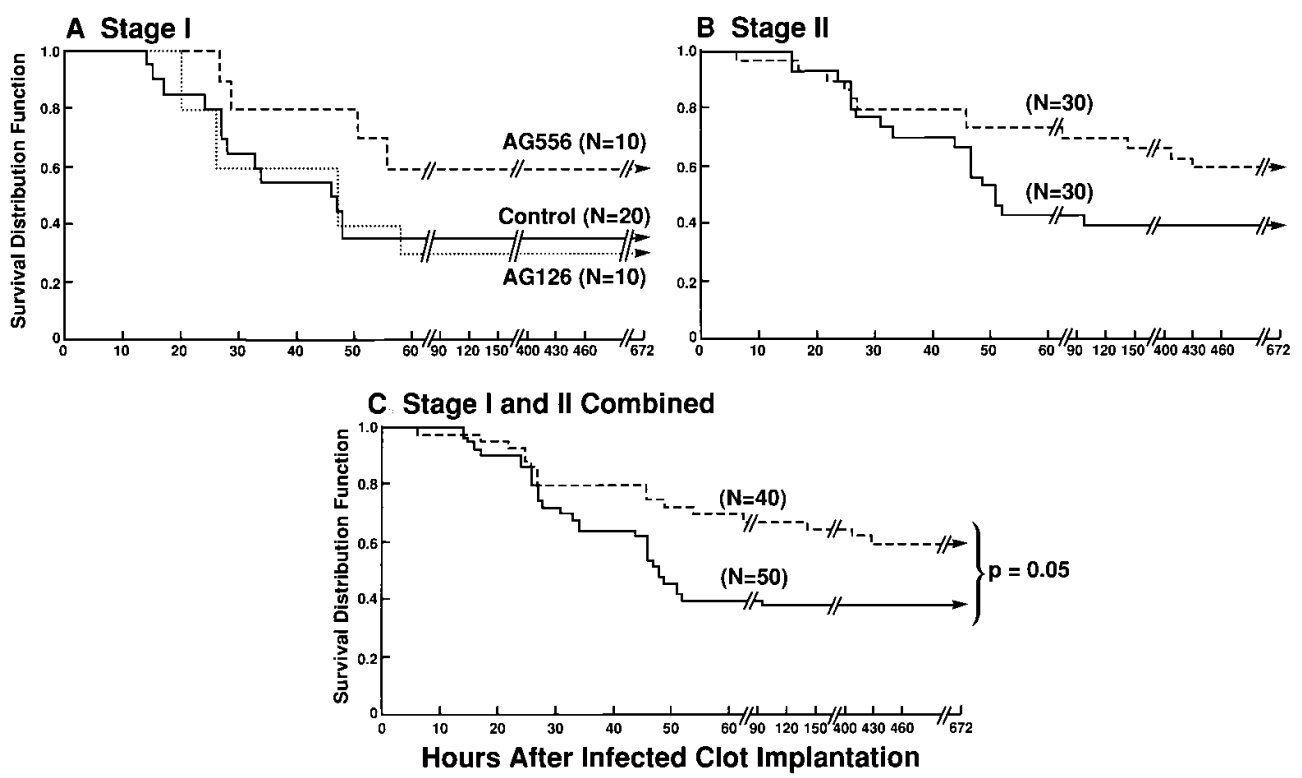

Figure 1. Survival versus time for AG 126, AG 556, and control-treated animals. $(A)$ The first 40 animals studied. Based on this result $(B)$ shows the next 60 animals determined to be studied (see statistical methods). (C) For the 90 animals treated with AG 556 or control vehicle in two stages, there was a significant beneficial effect on survival. controls (Fig. 2 for probability values). In AG 556-treated animals, only after $48 \mathrm{~h}$ was the mean $\mathrm{AaPO}_{2}$ significantly lower than controls. Comparing AG 556 versus controls, there were no other significant differences in any other cardiopulmonary parameter measured throughout ( $P=\mathrm{NS}$; data not shown).
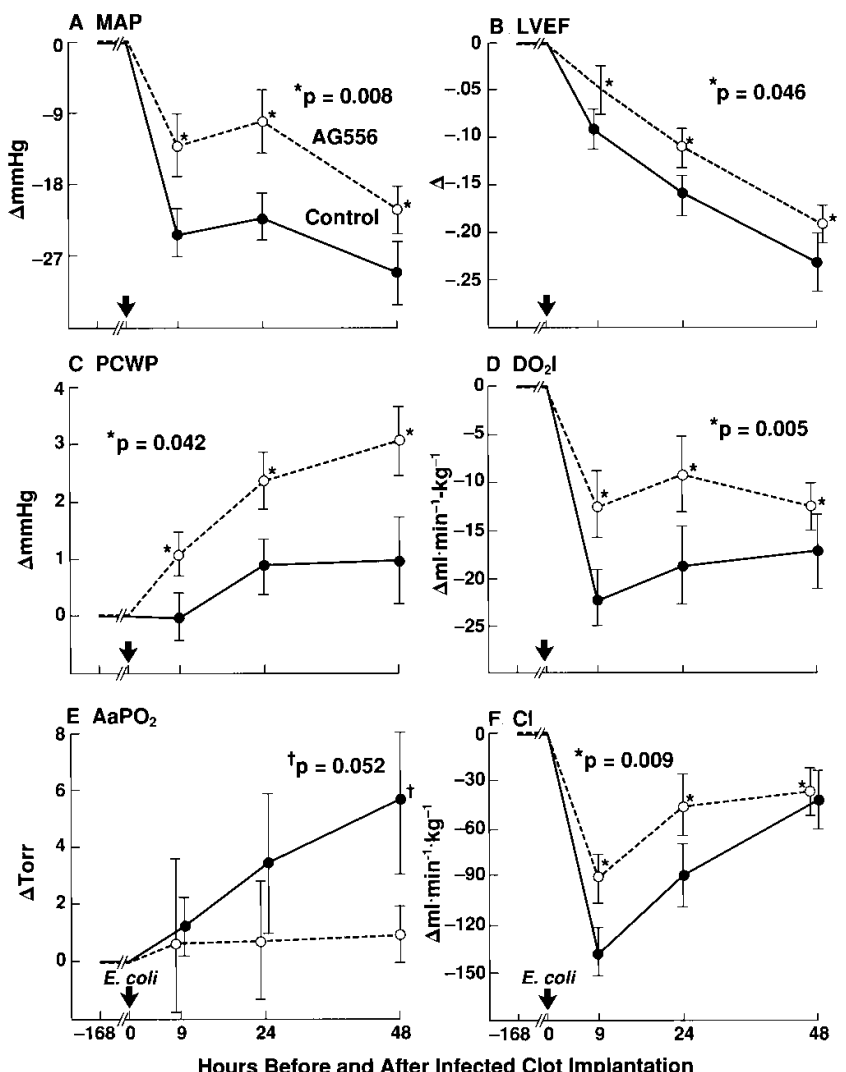

Hours Before and After Infected Clot Implantation

Figure 2. Serial mean \pm SE changes in cardiovascular and pulmonary parameters versus time. *A significant difference in the change from baseline to 9,24 , and $48 \mathrm{~h}$ combined compared with controls.

${ }^{\dagger}$ Indicates at this time point there was significant difference versus controls.
We tested the hemodynamic parameters significantly improved by AG 556 during sepsis for their ability to predict outcome. Fig. $3 \mathrm{~A}$ shows the correlations of each of these cardiopulmonary parameters with survival to give an indication of the strength of the predictive capabilities of each parameter. At $9 \mathrm{~h}$, for control and AG 556-treated animals alike, a higher MAP was significantly predictive of survival $(P=0.05)$. At 24 and $48 \mathrm{~h}$, a higher MAP, CI, and $\mathrm{DO}_{2} \mathrm{I}$ were significantly predictive of survival (all $P \leq 0.05$ ). At 24 and $48 \mathrm{~h}$, a higher EF,

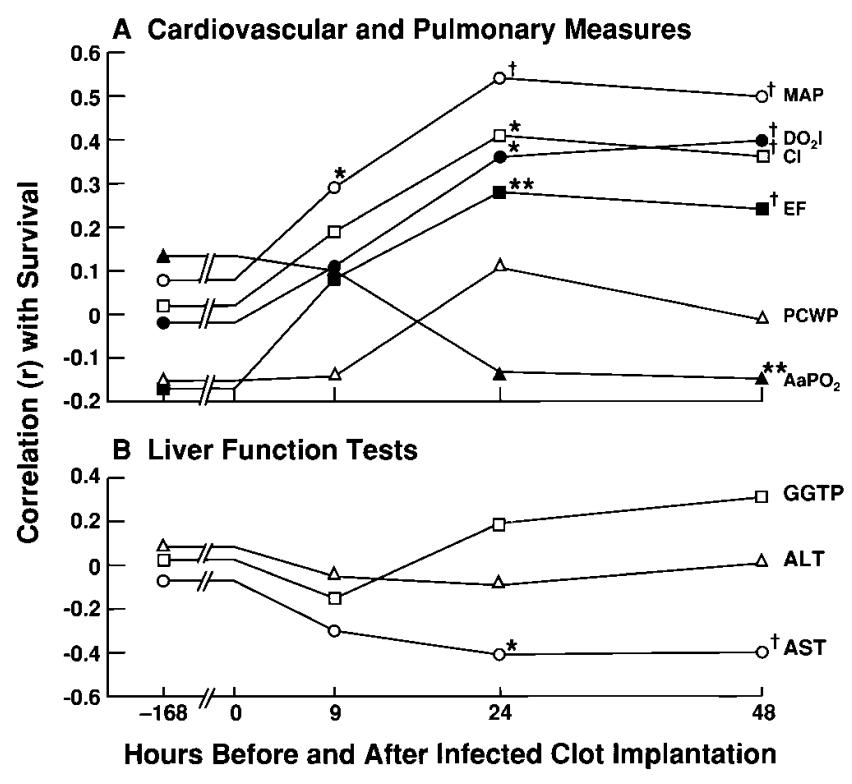

Figure 3. Serial correlations with survival of cardiovascular and pulmonary measure are shown in $A$, and liver function tests in $B$. This was done for comparative purposes to indicate the strength of the predictive capabilities of these parameters. *At this time point this variable was significantly predictive of outcome in all animals studied. ${ }^{\dagger}$ Indicates there was no significant change in the predictive capabilities of this parameter from the previous time point. **Indicates that this parameter was not significantly predictive of outcome at this time point but not in a range to indicate convincingly no effect $(P=0.06)$. 

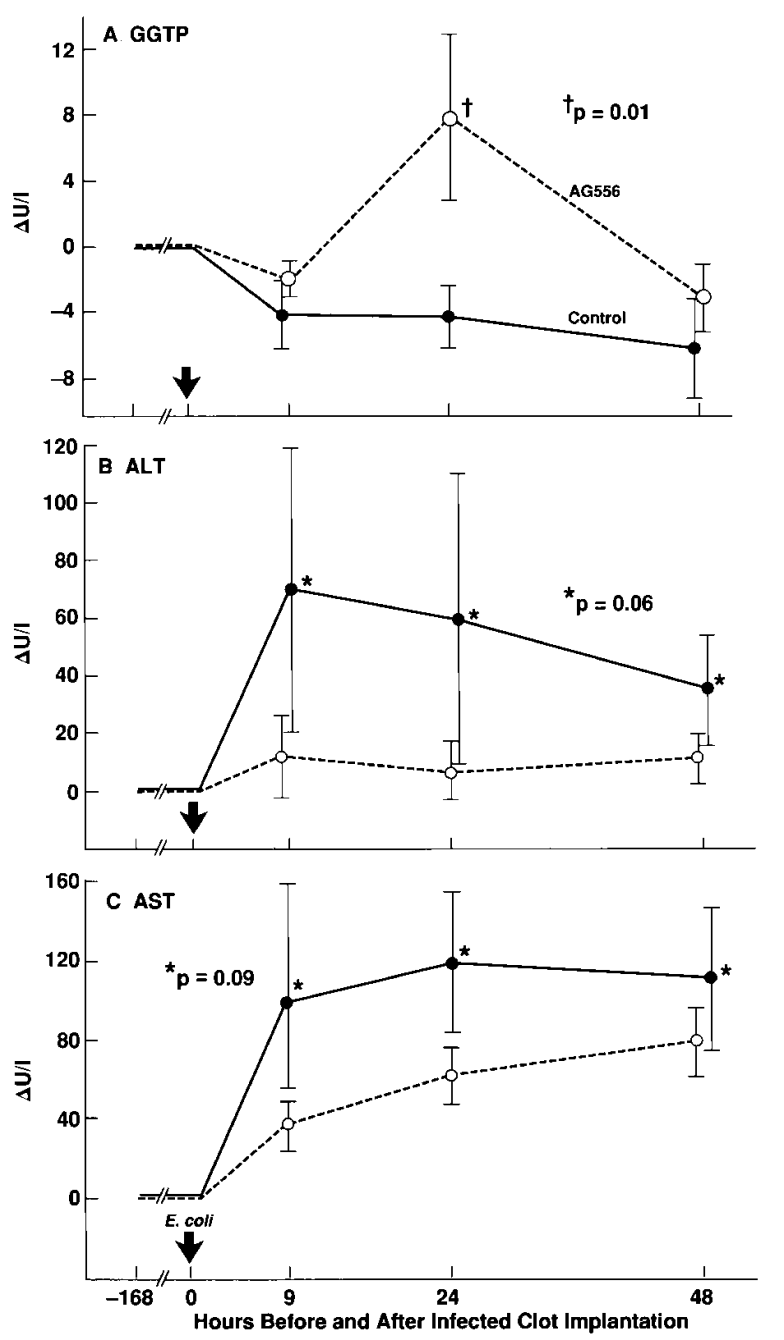

Figure 4. Format the same as Fig. 2 except now liver function tests are shown on the $y$ axis.

and at $48 \mathrm{~h}$, a lower $\mathrm{AaPO}_{2}$, were not significantly predictive of survival but were in a range suggestive of some effect (both $P=0.06$ ) on outcome. PCWP in AG 556 and control animals had no significant ability to predict outcome throughout $(P=\mathrm{NS})$.

Laboratory. At baseline, there were no significant differences in any of the laboratory parameters measured for AG 556 versus control animals ( $P=\mathrm{NS}$; data not shown). After clot implantation, there were no significant differences between groups in laboratory parameters except for liver function tests (Fig. 4; all other data not shown). At $24 \mathrm{~h}$ only, AG 556-treated animals had significantly higher mean GGTP levels than did controls. GGTP levels at $24 \mathrm{~h}$, however, were not significantly predictive of, nor correlated with, survival throughout (Fig. 3 B). Furthermore, at 9, 24, and 48 h combined, AG 556-treated animals did not have higher mean ALT and AST levels compared to controls $(P=\mathrm{NS})$. Moreover, a low AST in control and AG 556-treated animals alike was significantly predictive of survival at 24 and 48 h (both $P \leq 0.05$; Fig. $3 B$ ).

We noted in reviewing the GGTP data that only a small subset of animals at $24 \mathrm{~h}$ had high GGTP levels. To further
Table I. Mean ( \pm SE) Maximal Increase in TNF Levels $(\mathrm{ng} / \mathrm{ml})$ After Infected Clot Implantation

\begin{tabular}{lcc}
\hline Treatment group & Survivors & Nonsurvivors \\
\hline AG 556 & $6.4 \pm 2.0$ & $26.9 \pm 6.0$ \\
Controls & $9.8 \pm 4.6$ & $38.5 \pm 7.7$
\end{tabular}

AG 556 vs. controls, $P=0.03$; survivors vs. nonsurvivors, $P=0.001$.

characterize this subset of animals with the GGTP abnormality, we determined that at baseline, a value of $\geq 15 \mathrm{U} /$ liter was more than two standard deviations from the mean. At $24 \mathrm{~h}$ after clot implantation (mean \pm SE), GGTP levels were $\geq 15 \mathrm{U} /$ liter for $13 \%$ (5 of 38) of control, and 25\% (9 of 28) of AG 556treated animals. We next examined other laboratory parameters studied for significant differences between animals with high and low GGTP levels to determine if there was a recognizable pattern of abnormalities. Two types of analyses were done. First, we compared differences between high vs. low GGTP animals across treatment groups. If there were no significant differences, we then compared all animals irrespective of treatment group with high vs. low GGTP levels. Despite this analysis, no easily discernible pattern to indicate the source of this AG556 associated rise in GGTP during sepsis was discovered (data not shown).

TNF, endotoxins, blood cultures and tyrphostin AG 556 serum levels. The mean maximal increase in TNF levels after clot implantation was significantly higher in nonsurvivors vs. survivors in both AG 556-treated animals and controls $(P=$ 0.001; Table I). AG 556-treated animals, however, had significantly lower mean maximal increases in TNF levels in survivors and nonsurvivors compared with control-treated animals $(P=0.03$; Table I $)$.

Endotoxin levels were significantly elevated after clot implantation in all treatment groups (all $P \leq 0.05$ ), but showed no significant differences between AG 556 and control groups throughout $(P=\mathrm{NS}$; Fig. $5 A)$.

Quantitative blood bacterial counts rose in all treatment groups $6 \mathrm{~h}$ after clot implantation (all $P \leq 0.05$ ), but there was no statistically significant difference in the numbers of colonyforming units of E. coli per ml of blood comparing AG 556 and control groups throughout $(P=\mathrm{NS}$; Fig. $5 B)$.

Tyrphostin AG 556 levels (mean \pm SE) in treated animals were $1.00 \pm 0.49 \mu \mathrm{g} / \mathrm{ml}$ at $5 \mathrm{~min}$, and $0.28 \pm 0.08 \mu \mathrm{g} / \mathrm{ml}$ at $15 \mathrm{~min}$ after the first dose of AG 556 (immediately after clot implantation), and $0.61 \pm 0.17 \mu \mathrm{g} / \mathrm{ml}$ at $5 \mathrm{~min}$, and $0.17 \pm 0.03 \mu \mathrm{g} / \mathrm{ml}$ at 15 min after the second dose of AG 556 (6 h after clot implantation). Mean AG 556 levels were significantly elevated $(P=$ $0.01)$ in the AG 556-treated group compared to controls ( 0.0 $\mu \mathrm{g} / \mathrm{ml}$ throughout). In AG 556-treated animals, the mean levels of AG 556 at 5 min were significantly higher $(P=0.03)$ than at 15 min after infusion. Calculated serum half-life of the tyrphostin AG 556 was $9.2 \pm 4.5$ min immediately after infected clot implantation, and 7.4 $\pm 4.6 \mathrm{~min}$ at $6 \mathrm{~h}$.

In vitro experiments. Both AG $556(10-50 \mu \mathrm{M})$ and $\mathrm{AG}$ $126(20$ and $50 \mu \mathrm{M})$, when added to canine WBCs $(n=2)$ in vitro, significantly prevented LPS-induced increases in TNF levels $(P=0.04)$. The range of TNF levels produced was $<0.05$ $\mathrm{ng} / \mathrm{ml}$ (control); 20-23 ng/ml (LPS alone); and 2-8 ng/ml (AG 126 with LPS or AG 556 with LPS). 

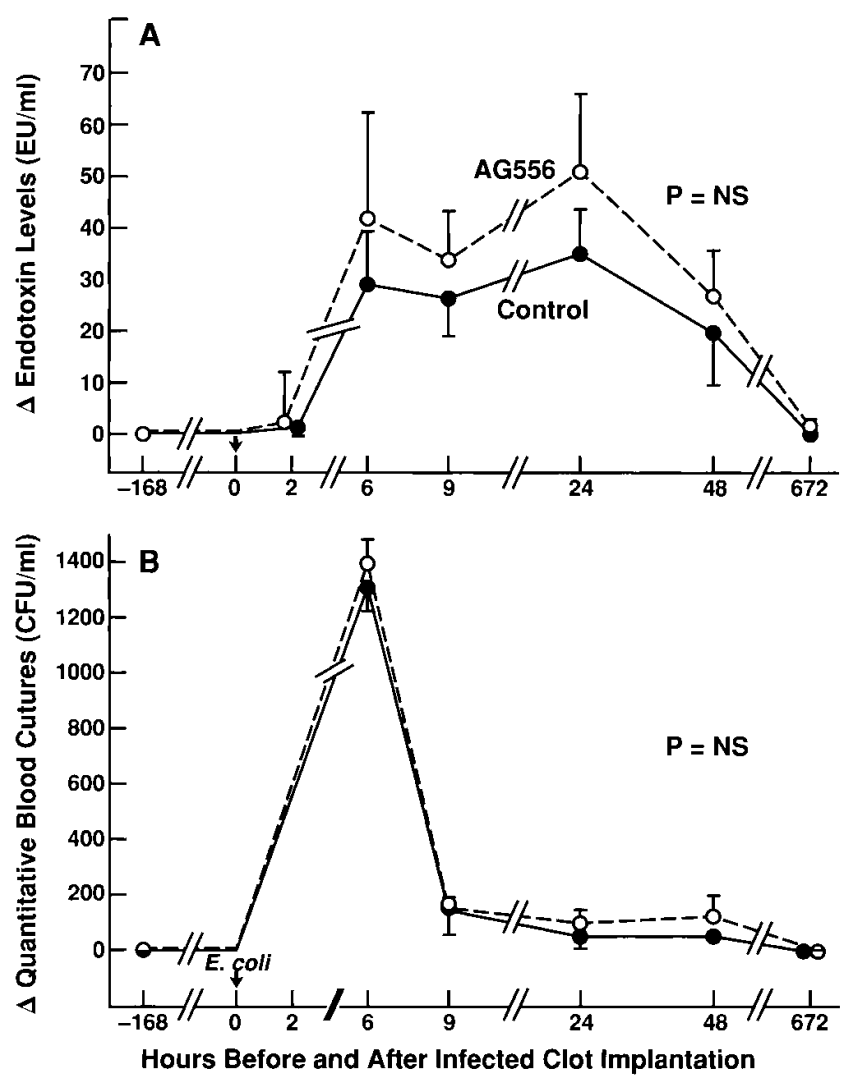

Figure 5. Serial mean $( \pm \mathrm{SE})$ changes in endotoxemia $(A)$ and bacteremia $(B)$ in AG 556-treated animals versus controls.

AG 556 and $A G 126$ administration to normal animals. AG $556(6.25 \mathrm{mg} / \mathrm{kg})$, when given to normal animals $(n=3)$, caused no significant hemodynamic or metabolic abnormalities over $24 \mathrm{~h}$ when measuring the same parameters outlined in Methods for infected animals compared to controls (DMSO alone; $n=7$ ) (data not shown). AG 126 , at doses $\geq 20 \mathrm{mg} / \mathrm{kg}$, caused nausea and vomiting during infusion. Otherwise, AG 126 at $10-20 \mathrm{mg} / \mathrm{kg}(n=3)$ caused no significant hemodynamic or metabolic abnormalities over a 24 -h period when compared with controls. DMSO, when given to normal animals at the doses used in this experiment $(0.5 \mathrm{mg} / \mathrm{kg}$ DMSO; $n=7)$, caused no significant changes in hemodynamic or laboratory parameters over a $24 \mathrm{~h}$ period compared to baseline (preDMSO).

\section{Discussion}

In a randomized, blinded, controlled trial in canines with gram-negative bacterial peritonitis, tyrphostin AG 556 significantly improved survival. This survival benefit was in addition to that produced by standard sepsis therapies of antibiotics, fluid support, and supplemental oxygen. AG 556 also prevented the multiple organ dysfunction of sepsis, as demonstrated by reductions in pulmonary, cardiac, and vascular abnormalities. In this study, organ injury was significantly predictive of outcome. Treatment with AG 556 had no effect on clearance of endotoxin or bacteria from the blood, but did lower serum TNF levels. These data are consistent with the conclusion that, independent of an antibacterial effect, and without impairing host defenses, AG 556 prevented multiorgan failure and death by inhibiting cell signaling pathways and subsequent cytokine production.

AG 556 exerted its beneficial effect on survival over an extended period of time. Of note, for the first $24 \mathrm{~h}$ AG 556treated animals had remarkably similar survival rates compared with controls. Only after $24 \mathrm{~h}$ did the survival effect of AG 556 begin to emerge. Also, it was not until $24 \mathrm{~h}$ after clot implantation that AG 556-associated reductions in organ injury became consistently predictive of survival. During this time, all animals received large but similar quantities of fluids, but vascular and cardiac filling pressures were higher in the AG-556 treated animals. Despite higher filling pressures, the alveolar-arterial oxygen gradient, a potential indirect indicator of vascular leak, was improved (lower) in AG 556-treated animals. One interpretation consistent with these data is that during bacteremia, inhibition of tyrosine kinase signal transduction by AG 556 blocked the initiation of harmful inflammatory responses, resulting in less vascular damage over time. This in turn yielded less vascular leak, intravascular volume loss, hypotension, organ injury, and death.

In contrast to AG 556, tyrphostin AG 126 provided no hemodynamic or survival advantage over control-treated animals when given after clot implantation. In previous experiments, AG 126 was effective in a murine model only when given before infection or endotoxin challenge (18). In contrast, AG 556 was effective both given before or after bacterial and endotoxin challenge in the murine model (22). Taken together, these studies suggest that AG 126, but not AG 556, must be given prophylactically to be effective. This timing difference between the two tyrphostins could be related to pharmacodynamic properties or relative doses. AG 556 contains an aliphatic chain which terminates in a phenyl moiety, making it more lipophilic than AG $126(18,22)$. It is possible that this lipophilic nature allows for better uptake by the cell, and thereby for more rapid intracellular distribution and blockade of signal transduction. Since the reported mechanism of action of tyrphostins involves blocking intracellular signal transduction $(18,19,22)$, effects of tyrphostins may not be dependent on circulating levels, but rather on intracellular uptake. Consistent with this hypothesis, the serum half-life of AG 556 was quite short (5-10 $\mathrm{min})$, but the effects on survival occurred over days.

A greater proportion of animals treated with AG 556 had a significant increase in GGTP levels compared to controls, but only at $24 \mathrm{~h}$. This GGTP abnormality was not associated with elevations in either ALT or AST, suggesting that this elevation might not be related to liver necrosis (Fig. 4). Further elevation of GGTP was not associated with mortality (Fig. $3 \mathrm{~B}$ ). In fact, the two animals with the highest GGTP levels survived. There were no baseline characteristics to explain why animals developed high GGTP levels. GGTP is found in multiple tissues, including hepatobiliary tree, pancreas, intestine, spleen, eye, seminal vesicles, and kidneys (33). In animals with GGTP elevations, there was no consistent pattern of changes associated with any other blood chemistries measured to suggest a clear source or etiology for this increase. The possibility remains that AG 556 may increase GGTP elevations in patients with sepsis, and future clinical trials should look closely at dose and timing of this agent in relation to potential effects on this enzyme and other measures of hepatic function. 
Three points are worth noting about this study. First, only one dosage of AG 556 was used in this experiment, and it was chosen based on experimental data in mice; it is not yet clear that this is the optimal dosing regimen for beneficial effects. Second, many previous studies of potential therapies for sepsis in this model have showed harm or no significant benefit (1, 27, 34-38). Conversely, antiendotoxin IgG monoclonal antibodies specific for the oligosaccharide side chain expressed by the infecting bacteria (E. coli 011:B4) were found to be effective in this model (39). AG 556 is the only other investigational agent given therapeutically that significantly prolonged survival over and above that observed with conventional antibiotic and cardiovascular support in this model (1, 27, 34-39). Lastly, AG 556 was given directly after bacterial clot implantation. Clinically it is not possible to know the exact onset of infection, but therapy is usually not begun until symptoms of infection are already present. In murine sepsis models, AG 556 was effective when given up to $2 \mathrm{~h}$ after bacterial challenge (22). Further preclinical studies are needed to determine whether tyrphostins would be effective if given at time points when symptoms are well established.

In summary, tyrphostin AG 556 reduced mortality and multiorgan dysfunction in our canine model of septic shock. Most previous clinical trials have focused on agents designed to inhibit a single circulating inflammatory mediator. This approach has not been clearly effective to date. Tyrphostins are designed to inhibit tyrosine phosphorylation, thereby inhibiting cell signal transduction. They have the potential to block cell activation caused by both cytokines and bacterial products. This new approach to treat sepsis could lead to clinical benefit in this lethal syndrome.

\section{Acknowledgments}

The authors thank Dr. David W. Alling for monitoring the study and reviewing the statistical analysis; Donald P. Dolan, Allen T. Hilton, Daniel Madden, and Stephen Richmond for providing excellent technical support during the study, and Dr. Victoria Hampshire and Dr. Kathleen Maltby for giving veterinary care.

\section{References}

1. Natanson, C., W.D. Hoffman, A.F. Suffredini, P.Q. Eichacker, and R.L. Danner. 1994. Selected treatment strategies for septic shock based on proposed mechanisms of pathogenesis. Ann. Intern. Med. 120:771-783.

2. Center for Disease Control. 1990. Increase in national hospital discharge survey rates for septicemia-United States 1979-1987. MMWR (Morb. Mort. Wkly Rep.). 39:31-34.

3. Abraham, E., R. Wunderink, H. Silverman, T.M. Perl, S. Nasraway, H. Levy, R. Bone, R. Wenzel, R. Balk, R. Allred, J.E. Pennington, and J.C. Wherry. 1995. Efficacy and safety of monoclonal antibody to human tumor necrosis factor $\alpha$ in patients with sepsis syndrome. JAMA. 273:934-941.

4. Fisher, C.J., J.M. Agosti, S.M. Opal, S.F. Lowry, R.A. Balk, J.C. Sadoff, E. Abraham, R.M.H. Schein, and E. Benjamen. 1996. Treatment of septic shock with the tumor necrosis factor receptor: Fc fusion protein. N. Engl. J. Med. 334:1697-1702.

5. McCloskey, R.V., R.C. Straub, R.C. Sanders, S.M. Smith, and C.R. Smith. 1994. Treatment of septic shock with human monoclonal antibody HA1A. Ann. Intern. Med. 121:1-5.

6. Fisher, C.J., S.M. Opal, J.F. Dhainaut, S. Stephans, J.L. Zimmerman, P. Nightingale, S.J. Harris, R.M. Schein, E.A. Panacek, C. Garrard, et al. 1993. Influence of an anti-tumor necrosis factor monoclonal antibody on cytokine levels in patients with sepsis. Crit. Care. Med. 21:318-327.

7. Fisher, C.J., J.F. Dhainaut, S.M. Opal, J.P. Pribble, R.A. Balk, G.J. Slotman, T.J. Iberti, E.C. Rackow, M.J. Shapiro, R.L. Greenman, et al. 1994. Recombinant human interleukin 1 receptor antagonist in the treatment of patients with sepsis syndrome: results from a randomized, double-blind placebo-controlled trial. JAMA 271:1836-1843.
8. Tracey, K.J., Y. Fong, D.G. Hesse, K.R. Manogue, A.T. Lee, G.C. Kuo, S.I. Lowry, and A. Cerami. 1987. Anti-cachectin/TNF monoclonal antibodies prevent septic shock during lethal bacteraemia. Nature (Lond.). 330:662-664.

9. Ohlsson, K., P. Bjork, M. Bergenfeldt, R. Hageman, and R.C. Thompson. 1990. IL-1 receptor antagonist reduces mortality from endotoxin shock. Nature (Lond.). 348:550-552.

10. Teng, N.N.H., H.S. Kaplan, J.M. Herbert, C. Moore, H. Douglas, A. Wunderlich, and A.I. Braude. 1985. Protection against gram-negative bacteremia and endotoxemia with human monoclonal IgM antibodies. Proc. Natl. Acad. Sci. USA. 82:1790-1794.

11. Natanson, C., P.W. Eichenholtz, R.L. Danner, P.Q. Eichacker, W.D. Hoffman, G.C. Kuo, S.M. Banks, T.J. MacVittie, and J.E. Parillo. 1989. Endotoxin and tumor necrosis factor challenges in dogs simulate the cardiovascular profile of human septic shock. J. Exp. Med. 169:823-832.

12. Okusawa, S., J.A. Gelfand, T. Ikejima, R.J. Connolly, and C.A Dinarello. 1988. Interleukin 1 induces a shock-like state in rabbits. Synergism with tumor necrosis factor and the effect of cyclooxygenase inhibition. J. Clin. Invest. 81:1162-1172.

13. Eichacker, P.Q., W.D. Hoffman, A. Farese, S.M. Banks, G.C. Kuo, T.J. MacVittie, and C. Natanson. 1991. Tumor necrosis factor but not interleukin-1 challenge in canines produces lethal pulmonary injury and sustained but reversible multiple organ dysfunction similar to human septic shock. J. Appl. Physiol. 71:1979-1989.

14. Smith, J.W. II, W.J. Urba, B.D. Curti, L.J. Elwood, R.G. Sties, J.E. Janik, W.H. Sharfman, L.L. Miller, F.G. Fenton, K.C. Conlon, et al. 1992. The toxic and hematologic effects of interleukin-1 alpha administered in a phase I trial to patients with advanced malignancies. J. Clin. Oncol. 10:1141-1152.

15. Suffredini, A.F., R.E. Fromm, M.M. Parker, M. Brenner, J.A. Kovacs, R.A. Wesley, and J.E. Parrillo. 1989. The cardiovascular response of normal humans to the administration of endotoxin. N. Engl. J. Med. 321:280-287.

16. Luce, J.M. 1993. Introduction of new technology into critical care practice: a history of monoclonal antibody against endotoxin. Crit. Care Med. 21: 1233-1241.

17. Dellinger, R.P. 1996. Post hoc analysis in sepsis trials: A formula for disappointment? Crit. Care Med. 24:727-729.

18. Novogrodsky, A., A. Vanichkin, M. Patya, A. Gazit, N. Osherov, and A. Levitzki. 1994. Prevention of lipopolysaccharide induced lethal toxicity by tyrosine kinase inhibitors. Science (Wash. DC). 264:1319-1322.

19. Yaish, P., A. Gazit, C. Gilon, and A. Levitzki. 1988. Blocking of EGFdependent cell proliferation by EGF receptor kinase inhibitors. Science (Wash. DC). 242:933-935.

20. Glaser, K.B., A. Sung, J. Bauer, and B.M. Weichman. 1992. Regulation of eicosanoid biosynthesis in the macrophage. J. Biol. Chem. 265:8658-8664.

21. Dong, Z., C.A. O'Brian, and I.J. Fidler. 1993. Activation of tumoricidal properties in macrophages by lipopolysaccharide requires protein-tyrosine kinase activity. J. Leukocyte Biol. 53:53-60.

22. Vanichkin, A., M. Patya, A. Gazit, A. Levitzki, and A. Novogrodsky 1996. Late administration of a lipophilic tyrosine kinase inhibitor prevents lipopolysaccharide and Escherichia coli induced lethal toxicity. J .Infect. Dis. 173: 927-933.

23. Guy, G.R., S.P. Chua, N.S. Wong, S.B. Ng, and Y.H. Tan. 1991. Interleukin 1 and tumor necrosis factor activate common multiple protein kinases in human fibroblasts. J. Biol. Chem. 266:14343-14352.

24. Natanson, C., M.P. Fink, H.K. Ballantine, T.J. MacVittie, J.J. Conklin, and J.E. Parrillo. 1986. Gram negative bacteremia produces both severe systolic and diastolic cardiac dysfunction in a canine model that simulates human septic shock. J. Clin. Invest. 78:259-270.

25. Natanson, C., R.L. Danner, R.J. Elin, J.M. Hosseini, K.W. Peart, S.M. Banks, T.J. MacVittie, R.I. Walker, and J.E. Parrillo. 1989. Role of endotoxemia in cardiovascular dysfunction and mortality. Escherichia coli and Staphylococcus aureus challenges in a canine model of human septic shock. J. Clin. Invest. 83:243-251.

26. Natanson, C., R.L. Danner, J.M. Reilly, M.I. Doerfler, W.D. Hoffman, G.L. Akin, J.M. Hosseini, S.M. Banks, R.J. Elin, T.J. MacVittie, and J.E. Parrillo. 1990. Antibiotics versus cardiovascular support in a canine model of human septic shock. Am. J. Physiol. 259:1440-1447.

27. Quezado, Z.M.N., C. Natanson, D.W. Alling, S.M. Banks, C.A. Koev, R.J. Elin, J.M. Hosseini, J.D. Bacher, R.L. Danner, and W.D. Hoffman. 1993. A controlled trial of HA-1A in a canine model of gram-negative septic shock. JAMA. 269:2221-2227.

28. Gazit, A., P. Yaish, C. Gilon, and A. Levitzki. 1989. Tyrphostins I: synthesis and biological activity of protein tyrosine kinases. J. Med. Chem. 32: 2344-2352.

29. Gazit, A., N. Osherov, I. Posner, P. Yaish, E. Poradosa, C. Gilon, and A Levitzki. 1991. Heterocyclic and alpha-substituted benzylidenemalononitrile tyrphostins as potent inhibitors of EGF receptor and ErbB2/neu tyrosine kinases. J. Med. Chem. 34:1896-1907.

30. Eichacker, P.Q., Y. Waisman, C. Natanson, A. Farese, W.D. Hoffman, S.M. Banks, and T.J. MacVittie. 1994. Cardiopulmonary effects of granulocyte colony stimulating factor in a canine model of sepsis. J. Appl. Physiol. 77(5): 2366-2373.

31. Bauer, P., and K. Kohne. 1994. Evaluation of experiments with adaptive 
interim analyses. Biometrics. 50:1029-1041.

32. Scheffe, H. 1959. The Analysis of Variance. John Wiley \& Sons, New York. 55-137.

33. Lieberman, M.W., R. Barrios, B.Z. Carter, G.M. Habib, R.M. Lebovitz, S. Rajagopalan, A.R. Sepulveda, Z.Z. Shi, and D.F. Wan. 1995. $\gamma$-Glutamyl transpeptidase. Am. J. Pathol. 147:1175-1185.

34. Natanson, C., W.D. Hoffman, C.A. Koev, D.P. Dolan, S.M. Banks, J. Bacher, R.L. Danner, H.G. Klein, and J.E. Parrillo. 1993. Plasma exchange does not improve survival in a canine model of septic shock. Transfusion (Bethesda). 33:243-248.

35. Quezado, Z.M.N., C. Natanson, S.M. Banks, C.A. Koev, R.L. Danner, R.J. Elin, J.H. Hosseini, J.D. Bacher, and W.D. Hoffman. 1993. Pentoxifyllene can increase tumor necrosis factor level and decrease survival in a canine model of gram negative septic shock. Crit. Care Med. 21(Suppl.):281.

36. Freeman, B.D., I. Yatsiv, C. Natanson, M.A. Solomon, Z.M.N. Quezado, R.L. Danner, S.M. Banks, and W.D. Hoffman. 1995. Continuous arterio- venous hemofiltration does not improve survival in a canine model of septic shock. J. Am. Coll. Surg. 180:286-292.

37. Quezado, Z.M.N., C. Natanson, W.D. Hoffman, W. Karzai, C.A. Koev, R.L. Danner, S.M. Banks, L. Wilson, and P.Q. Eichacker. 1995. Granulocyte colony stimulating factor(G-CSF) treatment at the onset of $E$. coli induced septic shock in canines. Am. J. Respir. Crit. Care Med. 151:447a. (Abstr.)

38. Eichacker, P.Q., W.D. Hoffman, A. Farese, R.L. Danner, A.F. Suffredini, Y. Waisman, S.M. Banks, L. Wilson, R. Rothlein, R.J. Elin, J.M. Hosseini, T.J. MacVittie, and C. Natanson. 1993. Antibody against leucocyte CD-18 adhesion complex worsens endotoxemia and cardiovascular dysfunction in antibiotic treated canines with septic shock. J. Appl. Physiol. 74:1885-1892.

39. Hoffman, W.D., M. Pollack, S.M. Banks, C.A. Koev, M.A. Solomon, R.L. Danner, N. Koles, G. Guelde, I. Yatsiv, T. Mouganis, et al. 1994. Distinct functional activities in canine septic shock of monoclonal antibodies specific for the O-polysaccharide and core regions of Escherichia coli lipopolysaccharide. J. Infect. Dis. 169:553-561. 